\title{
The subcellular compartmentalization of arginine metabolizing enzymes and their role in endothelial dysfunction
}

\author{
Feng Chen ${ }^{1}$, Rudolf Lucas ${ }^{1,2}$ and David Fulton ${ }^{1,2}$ * \\ 1 Vascular Biology Center, Georgia Regents University, Augusta, GA, USA \\ 2 Department of Pharmacology, Georgia Regents University, Augusta, GA, USA
}

\section{Edited by:}

Charles Dinarello, University of Colorado Health Sciences Center, USA

\section{Reviewed by:}

Sungwoo Ryoo, Kangwon National University, South Korea

Mark James Crabtree, University of Oxford, UK

\section{${ }^{*}$ Correspondence}

David Fulton, Vascular Biology Center, Georgia Regents University, 1459 Laney Walker Bvld., Augusta, GA 30912, USA

e-mail:dfulton@gru.edu
The endothelial production of nitric oxide (NO) mediates endothelium-dependent vasorelaxation and restrains vascular inflammation, smooth muscle cell proliferation, and platelet aggregation. Impaired production of $\mathrm{NO}$ is a hallmark of endothelial dysfunction and promotes the development of cardiovascular disease. In endothelial cells, NO is generated by endothelial nitric oxide synthase (eNOS) through the conversion of its substrate, l-arginine to I-citrulline. Reduced access to I-arginine has been proposed as a major mechanism underlying reduced eNOS activity and NO production in cardiovascular disease. The arginases (Arg1 and Arg2) metabolize l-arginine to generate l-ornithine and urea and increased expression of arginase has been proposed as a mechanism of reduced eNOS activity secondary to the depletion of l-arginine. Indeed, supplemental l-arginine and suppression of arginase activity has been shown to improve endothelium-dependent relaxation and ameliorate cardiovascular disease. However, this simple relationship is complicated by observations that l-arginine concentrations in endothelial cells remain sufficiently high to support NO synthesis. Accordingly, the subcellular compartmentalization of intracellular l-arginine into poorly interchangeable pools has been proposed to allow for the local depletion of pools or pockets of I-arginine. In agreement with this, there is considerable evidence supporting the importance of the subcellular localization of l-arginine metabolizing enzymes. In endothelial cells in vitro and in vivo, eNOS is found in discrete intracellular locations and the capacity to generate NO is heavily influenced by its localization inside the cell. Arg1 and Arg2 also reside in different subcellular environments and are thought to differentially influence endothelial function. The plasma membrane solute transporter, CAT-1 and the arginine recycling enzyme, arginosuccinate lyase, co-localize with eNOS and facilitate NO release. Herein, we highlight the importance of the subcellular location of eNOS and arginine transporting and metabolizing enzymes to NO release and cardiovascular disease.

Keywords: eNOS, I-arginine, nitric, arginase, CAT-1, ASL, ASS, I-citrulline

\section{ENDOTHELIAL DYSFUNCTION}

The past three decades have provided unprecedented gains in our understanding of vascular biology. It is now hard to conceive of a time when the vascular endothelium was thought to be a simple barrier, an inert layer of cells lining the lumen of blood vessels. However this was the prevailing view prior to 1981 and the world of vascular biology was irrevocably changed with Furchgott's discovery of an ability of the endothelium to direct changes in vasomotor function (1). In the time since, the depth and pace of research to understand the myriad functions of the endothelium has been remarkable. Not the least of these has been the discovery of endothelial nitric oxide synthase (eNOS) (2-4), an enzyme selectively expressed in the endothelial cells with the ability to generate nitric oxide $(\mathrm{NO})$ and thus regulate blood vessel tone (5). Dysfunction of the vascular endothelium is considered to be the harbinger of cardiovascular disease and precedes the development of overt symptoms $(6,7)$. Given the importance of eNOS and endogenous NO production to endothelial function, it is not surprising that considerable effort has been focused on the mechanisms influencing eNOS activity in cardiovascular disease. The primary enzymatic function of eNOS is to catalyze the NADPHdependent conversion of $\mathrm{L}$-arginine into $\mathrm{NO}$, a process shared by the two other NOS isoforms (8). Once formed, NO has an expansive array of cellular targets both locally in the endothelium to influence inflammatory signaling, metabolism, exocytosis, proliferation, motility, and survival, but also in adjacent cells such as vascular smooth muscle cells to decrease vasomotor tone, proliferation and migration, and in platelets to suppress aggregation (9). Loss of these functions promotes increased inflammation, thrombosis, high blood pressure, and vascular cell proliferation, processes that are intimately involved in the development of cardiovascular disease.

\section{L-ARGININE}

Because of the obligatory role of $\mathrm{L}$-arginine in NO synthesis, considerable attention has been focused on the importance of 
L-arginine availability in the vascular production of NO. Fueling this interest were early studies reporting that L-arginine could directly stimulate EDRF/NO synthesis (10-12) and that compromised endothelial function in cardiovascular disease states could be improved by supplementation with $\mathrm{L}$-arginine both in animals (13-17), healthy humans (18) and those with high cholesterol (19-21), cardiac transplantation (22), peripheral artery disease (23), pulmonary hypertension (24), and angina (25). Considerable evidence pointed toward L-arginine deficiency being a major rate limiting step in the synthesis of NO. However, the affinity of eNOS for L-arginine is low $(\sim 2-3 \mu \mathrm{M})$ (26) and the amount of L-arginine in endothelial cells is hundreds of times higher ( $\sim 840 \mu \mathrm{M})$ (27) suggesting that a substrate deficiency was an unlikely unitary cause of eNOS dysfunction and that additional mechanisms of dysfunction must exist.

\section{SUBCELLULAR LOCALIZATION OF eNOS}

The co-translational $N$-myristoylation (glycine 2) and posttranslational cysteine palmitoylation of eNOS (cysteines 15 and 26) enable membrane binding and the discrete subcellular targeting (28). In the endothelial cell, eNOS can be found predominantly localized to the perinuclear Golgi (29) and microdomains of the plasma membrane, including caveolae and lipid rafts $(30,31)$. eNOS has also been reported in other compartments, such as the mitochondria, the nucleus and the cytoskeleton $(32,33)$. The importance of location to eNOS function and cellular NO release was first demonstrated by mutations that prevent both myristoylation and palmitoylation resulting in an enzyme that is catalytically competent in activity assays outside the cell, but exhibits dramatically reduced capacity to generate NO in intact cells (29). Furthermore, the relative activity of eNOS varies depending on its intracellular location with the highest activity observed from eNOS at the plasma membrane, followed by outer membranes of the cis-Golgi and very low activity in the cytosol, nucleus, and mitochondria $(32,34,35)$. Given the dramatic ability of subcellular location to influence eNOS activity and NO release, it is not surprising that compartmentalization has been proposed as a major mechanism by which the local concentration of L-arginine can influence NO release (36).

\section{L-ARGININE TRANSPORTERS}

The concentration of $\mathrm{L}$-arginine in human plasma is $\sim 100$ $200 \mu \mathrm{M}$ (37) and higher concentrations, up to $840 \mu \mathrm{M}$ (27) can be found within the endothelial cell reflecting the existence of transport processes. A number of distinct transmembrane transporters exist on the plasma membrane of endothelial cells that mediate the predominantly sodium independent import of L-arginine via $y+$ and $\mathrm{y}+\mathrm{L}$ transporters. The major genes involved in $\mathrm{y}+$ import are CAT-1 (SLC7A1) and CAT-2 (SLC7A2), whereas for $\mathrm{y}+\mathrm{L}$ import, LAT1 (SLC7A7 and SLC3A2) and LAT2 (SLC7A6 and SLC3A2) are required (36). The presence of CAT-1 in plasmalemma caveolae and the ability of extracellular L-arginine to stimulate NO release in cells with abundant L-arginine levels has led to the hypothesis that L-arginine exists in poorly interchangeable subcellular compartments and reaches eNOS in sufficient concentrations via metabolite channeling (36). While there is suggestive data for the existence of these pools (38), direct evidence and a mechanism for
$\mathrm{L}$-arginine sequestration is lacking. A further wrinkle to this story is that the cationic amino acid transporter, CAT-1 can stimulate eNOS activity via direct binding rather than delivering abundant L-arginine to its catalytic doorstep (39).

\section{L-ARGININE RECYCLING}

Endothelial cells can maintain their L-arginine levels despite the continuous release of NO (40), suggesting the existence of mechanisms to recover substrate. Indeed, L-citrulline, the byproduct of eNOS-dependent NO generation, can be converted back to Larginine via the sequential actions of arginosuccinate synthase (ASS) and arginosuccinate lyase (ASL) (41). The co-localization of ASS/ASL with eNOS in plasma membrane caveolae suggests that $\mathrm{L}$-arginine recycling from $\mathrm{L}$-citrulline is a significant source of NO $(42,43)$. The importance of this pathway is revealed by impaired endothelium-dependent NO generation and increased blood pressure in humans and mice with ASL deficiency (44). Not only do ASL and ASS co-localize with eNOS, but they have been shown to bind directly and regulate eNOS activity (44). A caveat to these studies is that only a fraction of eNOS is present in plasma membrane caveolae and significant amounts of eNOS can be found on endomembranes such as the Golgi. It is not yet known if eNOS at the Golgi or other organelles are regulated by arginine regulatory enzymes in the same way as the plasma membrane/caveolae bound eNOS. Larginine can also be generated from the breakdown of proteins via both proteosomal and lysosomal pathways, which liberates L-arginine (45). The breakdown of proteins also liberates asymmetric methylated arginines, monomethylarginine (MMA), and asymmetric dimethylarginine (ADMA) which are potent substrate inhibitors of eNOS activity. The methylation of proteins is increased in cardiovascular disease, providing a source for the increased levels of MMA and ADMA via proteolysis (46). Methylated arginines are metabolized by the dimethylarginine dimethylaminohydrolases (DDAH1 and DDAH2). DDAH is found primarily in the cytosol (47) although there are reports of expression in the mitochondria (47) and nucleus (48). Accumulation of asymmetric methylated arginines results in a degree of eNOS-inhibition that is proportional to the ratio of $\mathrm{L}^{-}$ arginine/methylated arginine. The inhibition of eNOS can be relieved by supplementation with L-arginine leading to increased production of $\mathrm{NO}$ and improvement of endothelial function (49).

\section{ARGINASES}

Arginase I and Arginase II are homologous genes encoded by different chromosomes that share the catalytic function of converting L-arginine into urea and ornithine (50). A significant difference between Arginase I and Arginase II is their distinct subcellular distribution, with Arginase I detected predominantly in the cytosol and Arginase II within the mitochondria (51, 52). As enzymes that consume the substrate for eNOS, L-arginine, the arginases have been proposed as endogenous antagonists of eNOS. Increased expression and activity of Arginase I have been implicated in numerous cardiovascular diseases including diabetic retinopathy, asthma, coronary artery dysfunction during renovascular hypertension, and sickle cell disease (53-57) and Arginase 
II has been shown to be specifically increased in retinopathy of prematurity, human pulmonary arterial endothelial cells during hypertension, atherosclerosis, and in diabetic renal injury (5760). Numerous studies have shown that increased expression of arginase correlates with impaired NO synthesis and that inhibition of arginase increases NO production (53, 61, 62). However, this seemingly simple relationship between eNOS and the arginases is complicated by enzyme kinetics and L-arginine concentrations. The affinity of eNOS for arginine is relatively high $\left(K_{\mathrm{m}}=3 \mu \mathrm{M}\right)$, the affinity of arginase for $\mathrm{L}$-arginine relatively low $(2 \mathrm{mM})$ and the concentrations of intracellular L-arginine (300$800 \mu \mathrm{M})$ sufficient to support near maximal eNOS activity. Two explanations have been proposed to explain the inhibitory actions of arginase, one is the 1000-fold higher enzyme activity ( $\left.V_{\max }\right)$ and the other, the compartmentalization and regional deficiency of L-arginine (63). Vascular dysfunction achieved through the arginase-mediated depletion of $\mathrm{L}$-arginine can be reversed with L-arginine supplementation (64) but this also drives increased arginase activity.

\section{L-ARGININE SUPPLEMENTATION}

The preceding evidence has emphasized the important role Larginine plays in the maintenance of endothelial and cardiovascular function and is supported by studies showing that at least in the short-term; L-arginine supplementation can increase endothelial function and mitigate disease. However, more recent evidence suggests that chronic long term supplementation offers little benefit and may instead be harmful (65). The reasons for this are not well understood and likely to be numerous. Chronic exposure to high levels of NO can desensitize NO signaling, impair L-arginine import and increase vascular lesions and mortality (66-69). In contrast, inhibition of endogenous $\mathrm{NO}$ can increase sensitivity to NO donors and collectively this suggests that there is pushback when "pushing" NO signaling. Chronic supplementation with Larginine can also influence other pathways including the greater activation of iNOS (70) which unlike eNOS, is primarily constrained by substrate availability, and the increased expression and catalytic activity of the arginases due to their higher $K_{\mathrm{m}}$. A consequence of increased arginase activity is the production of ornithine and attendant elevation of $\mathrm{L}$-proline and the polyamines which can promote cell proliferation and maladaptive vascular remodeling (71).

\section{REFERENCES}

1. Furchgott RF, Zawadski JV. The obligatory role of the endothelial cells in the relaxation of arterial smooth muscle by acetylcholine. Nature (1980) 288:373-6. doi:10.1038/2883 $73 \mathrm{a} 0$

2. Nishida K, Harrison DG, Navas JP, Fisher AA, Dockery SP, Uematsu $\mathrm{M}$, et al. Molecular cloning and characterization of the constitutive bovine aortic endothelial cell nitric oxide synthase. $J$

\section{CONCLUSION}

L-Arginine is a semi-essential amino acid with a number of important roles in the endothelium including the ability to drive NO production. The compartmentalization of arginine metabolizing and transporting enzymes has important ramifications for endothelial function and cardiovascular health. L-arginine transporters and recycling enzymes have been found in the same intracellular location as eNOS, and some have been found to directly bind eNOS. However, whether this proximity is necessary for providing eNOS with ready access to L-arginine is questionable. Catalytically inactive forms of ASL and substrate-inhibition of CAT-1 do not prevent the ability of these enzymes/transporters to stimulate NO release and this suggests they instead play a structural role in the activation of eNOS. The arginases, which compete for and metabolize L-arginine, particularly when L-arginine is in high abundance, do not reside in the same intracellular locations as eNOS (and presumably do not physically associate) and thus are unlikely to exclusively regulate $\mathrm{L}$-arginine content in pools accessible to eNOS. Instead a more important role of the arginases may be to generate L-proline and polyamines that can negatively impact endothelial and vascular function. The accumulation of asymmetric methylated arginines occurs at the major sites of protein degradation, the proteasome and lysosome, and like the cytosolic DDAH, they are not thought to be in close proximity to eNOS. Frequently underappreciated is the important role eNOS subcellular location has on NO release. Targeting eNOS to the plasma membrane supports the highest levels of NO production followed by the Golgi and the cytoplasm (35). Rendering eNOS insensitive to calcium overrides the effects of intracellular location on eNOS activity and suggests that local calcium and not L-arginine, is the major determinant of efficient NO release $(32,72)$. While compartmentalization may not be a critical mechanisms by which L-arginine influences eNOS activity, its ability to increase NO release is well documented. However, the failure of supplemental $\mathrm{L}$-arginine to improve cardiovascular health may be considered another lesson learned of why too much of a good thing can be bad. Chronic high levels of NO can result in the refractoriness of its targets to respond and is well documented in vascular smooth muscle. Mechanisms that temporarily restrict eNOS activity such as caveolin-1 or the location of eNOS on membranes of the Golgi enable efficient production of $\mathrm{NO}$ in the right amount at the right time for the right response.

encoding endothelial cell nitric oxide synthase. J Biol Chem (1992) 267(22):15274-6

5. Förstermann U, Sessa WC. Nitric oxide synthases: regulation and function. Eur Heart $J$ (2012) 33(7):829-37. doi:10.1093/ eurheartj/ehr304 837a-837d,

6. Celermajer DS, Sorensen KE, Gooch VM, Spiegelhalter DJ, Miller OI, Sullivan ID, et al. Noninvasive detection of endothelial dysfunction in children and adults at risk of atherosclerosis.
Lancet (1992) 340(8828):11115. doi:10.1016/0140-6736(92) 93147-F

7. Drexler H. Endothelial dysfunction: clinical implications. Prog Cardiovasc Dis (1997) 39(4):287$324 . \quad$ doi:10.1016/S00330620(97)80030-8

a distinct constitutive enzyme isoform. Proc Natl Acad Sci doi:10.1073/pnas.89.14.6348

4. Sessa WC, Harrison JK, Barber CM, Zeng D, Durieux ME, D'Angelo DD, et al. Molecular cloning and expression of a cDNA
8. Alderton WK, Cooper CE Knowles RG. Nitric oxide synthases: structure, function and inhibition. Biochem $J \quad$ (2001) 357(Pt 3):593-615. doi:10.1042/0264-6021:3570593 
9. Albrecht EW, Stegeman CA, Heeringa P, Henning RH, van Goor H. Protective role of endothelial nitric oxide synthase. $J$ Pathol (2003) 199(1):8-17. doi:10.1002/path.1250

10. Sakuma I, Stuehr DJ, Gross SS, Nathan C, Levi R. Identification of arginine as a precursor of endothelium-derived relaxing factor. Proc Natl Acad Sci U S A (1988) 85(22):8664-7. doi:10.1073/pnas.85.22.8664

11. Gold ME, Wood KS, Buga GM, Byrns RE, Ignarro LJ. L-arginine causes whereas L-argininosuccinic acid inhibits endotheliumdependent vascular smooth muscle relaxation. Biochem Biophys Res Commun (1989) 161(2):536-43. doi:10.1016/0006291X(89)92632-6

12. Fineman JR, Chang R, Soifer SJ. L-Arginine, a precursor of EDRF in vitro, produces pulmonary vasodilation in lambs. Am J Physiol (1991) 261 (5 Pt 2):H1563-9.

13. Girerd XJ, Hirsch AT, Cooke JP, Dzau VJ, Creager MA. L-arginine augments endotheliumdependent vasodilation in cholesterol-fed rabbits. Circ Res (1990) 67(6):1301-8. doi:10.1161/ 01.RES.67.6.1301

14. Cooke JP, Andon NA, Girerd XJ, Hirsch AT, Creager MA. Arginine restores cholinergic relaxation of hypercholesterolemic rabbit thoracic aorta. Circulation (1991) 83(3):1057-62. doi:10.1161/01.CIR.83.3.1057

15. Aji W, Ravalli S, Szabolcs M, Jiang XC, Sciacca RR, Michler $\mathrm{RE}$, et al. L-arginine prevents xanthoma development and inhibits atherosclerosis in LDL receptor knockout mice. Circulation (1997) 95(2):430-7. doi:10.1161/01.CIR.95.2.430

16. Morikawa E, Rosenblatt S, Moskowitz MA. L-arginine dilates rat PIAL arterioles by nitric oxide-dependent mechanisms and increases blood flow during focal cerebral ischaemia. Br J Pharmacol (1992) 107(4):905-7. doi:10.1111/j.14765381.1992.tb13382.x

17. Pieper GM, Peltier BA. Amelioration by L-arginine of a dysfunctional arginine/nitric oxide pathway in diabetic endothelium. J Cardiovasc Pharmacol (1995) 25(3):397-403. doi:10.1097/ 00005344-199503000-00008

18. Lerman A, Burnett JC Jr, Higano ST, McKinley LJ, Holmes DR Jr. Long-term L-arginine supplementation improves small-vessel coronary endothelial function in humans. Circulation (1998) 97(21):2123-8. doi:10.1161/01.CIR.97.21.2123

19. Drexler H, Zeiher AM, Meinzer $\mathrm{K}$, Just $\mathrm{H}$. Correction of endothelial dysfunction in coronary microcirculation of hypercholesterolaemic patients by L-arginine. Lancet (1991) 338(8782-8783):1546-50. doi:10. 1016/0140-6736(91)92372-9

20. Creager MA, Gallagher SJ, Girerd XJ, Coleman SM, Dzau VJ, Cooke JP. L-arginine improves endothelium-dependent vasodilation in hypercholesterolemic humans. J Clin Invest (1992) 90(4):1248-53. doi:10.1172/ JCI115987

21. Clarkson P, Adams MR, Powe AJ, Donald AE, McCredie R, Robinson J, et al. Oral Larginine improves endotheliumdependent dilation in hypercholesterolemic young adults. $J$ Clin Invest (1996) 97(8):1989-94. doi:10.1172/JCI118632

22. Drexler H, Fischell TA, Pinto FJ, Chenzbraun A, Botas J, Cooke JP, et al. Effect of L-arginine on coronary endothelial function in cardiac transplant recipients. Relation to vessel wall morphology. Circulation (1994) 89(4):1615-23. doi:10.1161/01.CIR.89.4.1615

23. Lekakis JP, Papathanassiou S, Papaioannou TG, Papamichael CM, Zakopoulos N, Kotsis V, et al. Oral L-arginine improves endothelial dysfunction in patients with essential hypertension. Int J Cardiol (2002) 86(23):317-23. doi:10.1016/S01675273(02)00413-8

24. Nagaya N, Uematsu M, Oya H, Sato N, Sakamaki F, Kyotani $\mathrm{S}$, et al. Short-term oral administration of L-arginine improves hemodynamics and exercise capacity in patients with precapillary pulmonary hypertension. Am J Respir Crit Care Med (2001) 163(4):887-91. doi:10.1164/ajrccm.163.4.2007116

25. Piatti P, Fragasso G, Monti LD, Setola E, Lucotti P, Fermo I, et al. Acute intravenous Larginine infusion decreases endothelin-1 levels and improves endothelial function in patients with angina pectoris and normal coronary arteriograms: correlation with asymmetric dimethylarginine levels. Circulation (2003) 107(3):429-36.
doi:10.1161/01.CIR.0000046489. 24563.79

26. McCabe TJ, Fulton D, Roman LJ, Sessa WC. Enhanced electron flux and reduced calmodulin dissociation may explain "calcium-independent" eNOS activation by phosphorylation. $J$ Biol Chem (2000) 275(9):6123-8. doi:10.1074/jbc.275.9.6123

27. Baydoun AR, Emery PW, Pearson JD, Mann GE. Substratedependent regulation of intracellular amino acid concentrations in cultured bovine aortic endothelial cells. Biochem Biophys Res Commun (1990) 173(3):940-8. doi:10.1016/S0006291X(05)80876-9

28. Liu J, Hughes TE, Sessa WC The first 35 amino acids and fatty acylation sites determine the molecular targeting of endothelial nitric oxide synthase into the Golgi region of cells: a green fluorescent protein study. J Cell Biol (1997) 137:1525-35. doi:10.1083/jcb.137.7.1525

29. Sessa WC, García-Cardeña G, Liu J, Keh A, Pollock JS, Bradley J, et al. The Golgi association of endothelial nitric oxide synthase is necessary for the efficient synthesis of nitric oxide. J Biol Chem (1995) 270(30):176414. doi:10.1074/jbc.270.30 17641

30. Shaul PW, Smart EJ, Robinson LJ, German Z, Yuhanna IS, Ying Y, et al. Acylation targets emdothelial nitric-oxide synthase to plasmalemmal caveolae. J Biol Chem (1996) 271(11):6518-22. doi:10.1074/jbc.271.11.6518

31. Liu J, Garcia-Cardena G, Sessa WC. Palmitoylation of endothelial nitric oxide synthase is necessary for optimal stimulated release of nitric oxide: implications for caveolae localization. Biochemistry (1996) 35(41):13277-81. doi:10.1021/bi961720e

32. Jagnandan D, Sessa WC, Fulton D. Intracellular location regulates calcium-calmodulin-dependent activation of organelle-restricted eNOS. Am J Physiol Cell Physiol (2005) 289(4):C1024-33. doi:10.1152/ajpcell.00162.2005

33. Kondrikov D, Fonseca FV, Elms S, Fulton D, Black SM, Block $\mathrm{ER}$, et al. Beta-actin association with endothelial nitricoxide synthase modulates nitric oxide and superoxide generation from the enzyme. $J$ Biol Chem (2010) 285(7):4319-27. doi:10.1074/jbc.M109.063172
34. Gonzalez E, Kou R, Lin AJ, Golan DE, Michel T. Subcellular targeting and agonist-induced site-specific phosphorylation of endothelial nitric-oxide synthase. $J$ Biol Chem (2002) 277(42):39554-60. doi:10.1074/jbc.M207299200

35. Zhang Q, Church JE, Jagnandan D, Catravas JD, Sessa WC, Fulton D. Functional relevance of Golgi- and plasma membranelocalized endothelial NO synthase in reconstituted endothelial cells. Arterioscler Thromb Vasc Biol (2006) 26(5):1015-21. doi:10.1161/01.ATV.0000216044. 49494.c4

36. Closs EI, Simon A, Vékony N, Rotmann A. Plasma membrane transporters for arginine. J Nutr (2004) 134(10 Suppl):2752S-9. discussion 2765S-2767S,

37. Wu G, Morris SM Jr. Arginine metabolism: nitric oxide and beyond. Biochem J (1998) 336(Pt 1):1-17.

38. Simon A, Plies L, Habermeier A, Martiné U, Reining M, Closs EI. Role of neutral amino acid transport and protein breakdown for substrate supply of nitric oxide synthase in human endothelial cells. Circ Res (2003) 93(9):813-20. doi:10.1161/01.RES.0000097761. 19223.0D

39. Li C, Huang W, Harris MB, Goolsby JM, Venema RC. Interaction of the endothelial nitric oxide synthase with the CAT1 arginine transporter enhances NO release by a mechanism not involving arginine transport. Biochem J (2005) 386(Pt 3):56774. doi:10.1042/BJ20041005

40. Mitchell JA, Hecker M, Anggård EE, Vane JR. Cultured endothelial cells maintain their L-arginine level despite the continuous release of EDRF. Eur J Pharmacol (1990) 182(3):573-6. doi:10.1016/00142999(90)90058-E

41. Hecker M, Sessa WC, Harris HJ, Anggård EE, Vane JR. The metabolism of L-arginine and its significance for the biosynthesis of endothelium-derived relaxing factor: cultured endothelial cells recycle $\mathrm{L}$-citrulline to $\mathrm{L}$ arginine. Proc Natl Acad Sci US A (1990) 87(21):8612-6. doi:10.1073/pnas.87.21.8612

42. Flam BR, Hartmann PJ, HarrellBooth M, Solomonson LP, Eichler DC. Caveolar localization of arginine regeneration enzymes, 
argininosuccinate synthase, and lyase, with endothelial nitric oxide synthase. Nitric Oxide (2001) 5(2):187-97. doi:10.1006/niox.2001.0340

43. Solomonson LP, Flam BR, Pendleton LC, Goodwin BL, Eichler DC. The caveolar nitric oxide synthase/arginine regeneration system for NO production in endothelial cells. $J$ Exp Biol (2003) 206(Pt 12):2083-7. doi:10.1242/jeb.00361

44. Erez A, Nagamani SC, Shchelochkov OA, Premkumar MH, Campeau PM, Chen Y, et al. Requirement of argininosuccinate lyase for systemic nitric oxide production. Nat Med (2011) 17(12):1619-26. doi:10.1038/nm.2544

45. Karbach S, Simon A, Slenzka A, Jaenecke I, Habermeier A, Martiné $\mathrm{U}$, et al. Relative contribution of different l-arginine sources to the substrate supply of endothelial nitric oxide synthase. $J \mathrm{Mol}$ Cell Cardiol (2011) 51(5):855-61. doi:10.1016/j.yjmcc.2011.07.024

46. Miyazaki $\mathrm{H}$, Matsuoka $\mathrm{H}$, Cooke JP, Usui M, Ueda S, Okuda S, et al. Endogenous nitric oxide synthase inhibitor: a novel marker of atherosclerosis. Circulation (1999) 99(9):1141-6. doi:10.1161/01.CIR.99.9.1141

47. Birdsey GM, Leiper JM, Vallance P. Intracellular localization of dimethylarginine dimethylaminohydrolase overexpressed in an endothelial cell line. Acta Physiol Scand (2000) 168(1):73-9. doi:10.1046/j.1365201x.2000.00672.x

48. Chen Y, Li Y, Zhang P, Traverse JH, Hou M, Xu X, et al. Dimethylarginine dimethylaminohydrolase and endothelial dysfunction in failing hearts. Am J Physiol Heart Circ Physiol (2005) 289(5):H2212-9. doi:10.1152/ajpheart.00224.2005

49. Bode-Boger SM, Scalera F, Ignarro LJ. The L-arginine paradox: Importance of the L-arginine/asymmetrical dimethylarginine ratio. Pharmacol Ther (2007) 114(3):295-306. doi: 10.1016/j.pharmthera.2007.03.002

50. Morris SM Jr. Regulation of enzymes of the urea cycle and arginine metabolism. Annu Rev Nutr (2002) 22:87-105. doi:10.1146/ annurev.nutr.22.110801.140547

51. Jenkinson CP, Grody WW, Cederbaum SD. Comparative properties of $\begin{gathered}\text { arginases. } \\ \text { Comp Biochem Physiol B }\end{gathered}$ Biochem Mol Biol (1996) 114(1):107-32. doi:10.1016/03050491(95)02138-8

52. Morris SM Jr, Bhamidipati D, Kepka-Lenhart D. Human type II arginase: sequence analysis and tissue-specific expression. Gene (1997) 193(2):157-61. doi:10. 1016/S0378-1119(97)00099-1

53. Romero MJ, Iddings JA, Platt DH, Ali MI, Cederbaum SD, Stepp DW, et al. Diabetes-induced vascular dysfunction involves arginase I. Am J Physiol Heart Circ Physiol (2011) 302(1):H159-66. doi:10.1152/ajpheart.00774.2011

54. Morris CR, Kato GJ, Poljakovic M, Wang X, Blackwelder WC, Sachdev $\mathrm{V}$, et al. Dysregulated arginine metabolism, hemolysis-associated pulmonary hypertension, and mortality in sickle cell disease. JAMA (2005) 294(1):81-90. doi:10.1001/jama.294.19.2433-b

55. Zimmermann $\mathrm{N}$, King NE, Laporte J, Yang M, Mishra A, Pope SM, et al. Dissection of experimental asthma with DNA microarray analysis identifies arginase in asthma pathogenesis. $J$ Clin Invest (2003) 111(12):1863-74. doi:10.1172/JCI17912

56. Zhang C, Hein TW, Wang W, Miller MW, Fossum TW, McDonald MM, et al. Upregulation of vascular arginase in hypertension decreases nitric oxide-mediated dilation of coronary arterioles. Hypertension (2004) 44(6):935-43. doi:10.1161/ 01.HYP.0000146907.82869.f2

57. Morris SM Jr, Gao T, Cooper TK, Kepka-Lenhart D, Awad AS. Arginase-2 mediates diabetic renal injury. Diabetes (2011) 60(11):3015-22. doi:10.2337/db11-0901

58. Xu W, Kaneko FT, Zheng S, Comhair SA, Janocha AJ, Goggans $\mathrm{T}$, et al. Increased arginase II and decreased NO synthesis in endothelial cells of patients with pulmonary arterial hypertension. FASEB J (2004) 18(14):1746-8.

59. Narayanan SP, Suwanpradid J, Saul A, Xu Z, Still A, Caldwell RW, et al. Arginase 2 deletion reduces neuro-glial injury and improves retinal function in a model of retinopathy of prematurity. PLoS ONE (2011) 6(7):e22460. doi: 10.1371/journal.pone.0022460
60. Ryoo S, Berkowitz DE, Lim HK. Endothelial arginase II and atherosclerosis. Korean Anesthesiol (2011) 61(1):3-11. doi:10.4097/kjae.2011.61.1.3

61. Berkowitz DE, White R, Li D, Minhas KM, Cernetich A, Kim S, et al. Arginase reciprocally regulates nitric oxide synthase activity and contributes to endothelial dysfunction in aging blood vessels. Circulation (2003) 108(16):2000-6. doi:10.1161/01.CIR.0000092948. 04444.C7

62. Ryoo S, Gupta G, Benjo A, Lim HK, Camara A, Sikka G, et al. Endothelial arginase II: a novel target for the treatment of atherosclerosis. Circ Res (2008) 102(8):923-32. doi:10.1161/CIRCRESAHA.107.16 9573

63. Morris SM Jr. Recent advances in arginine metabolism: roles and regulation of the arginases. $\mathrm{Br} \mathrm{J}$ Pharmacol (2009) 157(6):92230. doi:10.1111/j.1476-5381. 2009.00278.x

64. Johnson FK, Johnson RA, Peyton KJ, Durante W. Arginase inhibition restores arteriolar endothelial function in Dahl rats with salt-induced hypertension. Am $J$ Physiol Regul Integr Comp Physiol (2005) 288(4):R1057-62. doi:10.1152/ajpregu.00758.2004

65. Wilson AM, Harada R, Nair $\mathrm{N}$, Balasubramanian $\mathrm{N}$, Cooke JP. L-arginine supplementation in peripheral arterial disease no benefit and possible harm. Circulation (2007) 116(2):188-95. doi:10.1161/CIRCULATIONAHA 106.683656

66. Abou-Mohamed G, Kaesemeyer WH, Caldwell RB, Caldwell RW. Role of L-arginine in the vascular actions and development of tolerance to nitroglycerin. $\mathrm{Br} J$ Pharmacol (2000) 130(2):211-8. doi:10.1038/sj.bjp.0703293

67. Bult H, De Meyer GR, Herman AG. Influence of chronic treatment with a nitric oxide donor on fatty streak development and reactivity of the rabbit aorta. $\mathrm{Br} \mathrm{J}$ Pharmacol (1995) 114(7):137182. doi:10.1111/j.1476-5381 1995.tb13358.x

68. De Meyer GR, Bult H, Kockx MM, Herman AG. The effect of chronic treatment with $\mathrm{NO}$ donors during intimal thickening and fatty streak formation.
Biofactors (1997) 6(2):209-15. doi:10.1002/biof.5520060215

69. Stayner LT, Dannenberg AL, Thun $\mathrm{M}$, Reeve G, Bloom TF, Boeniger $\mathrm{M}$, et al. Cardiovascular mortality among munitions workers exposed to nitroglycerin and dinitrotoluene. Scand J Work Environ Health (1992) 18(1):34-43. doi:10.5271/sjweh.1610

70. Chen J, Kuhlencordt P, Urano F, Ichinose H, Astern J, Huang PL. Effects of chronic treatment with L-arginine on atherosclerosis in apoE knockout and apoE/inducible NO synthase double-knockout mice. Arterioscler Thromb Vasc Biol (2003) 23(1):97-103. doi:10.1161/ 01.ATV.0000040223.74255.5A

71. Teerlink T. Letter by Teerlink regarding article, "L-arginine supplementation in peripheral arterial disease: no benefit and possible harm." Circulation (2008) 117(6):e157. doi:10.1161/ CIRCULATIONAHA.107.729830 author reply e158.

72. Church JE, Fulton D. Differences in eNOS activity because of subcellular localization are dictated by phosphorylation state rather than the local calcium environment. $J$ Biol Chem (2006) 281(3):1477-88 doi:10.1074/jbc.M505968200

Conflict of Interest Statement: The authors declare that the research was conducted in the absence of any commercial or financial relationships that could be construed as a potential conflict of interest.

Received: 13 April 2013; accepted: 24 June 2013; published online: 09 July 2013.

Citation: Chen F, Lucas $R$ and Fulton $D$ (2013) The subcellular compartmentalization of arginine metabolizing enzymes and their role in endothelial dysfunction. Front. Immunol. 4:184. doi: 10.3389/fimmu.2013.00184

This article was submitted to Frontiers in Inflammation, a specialty of Frontiers in Immunology.

Copyright (C) 2013 Chen, Lucas and Fulton. This is an open-access article distributed under the terms of the Creative Commons Attribution License, which permits use, distribution and reproduction in other forums, provided the original authors and source are credited and subject to any copyright notices concerning any third-party graphics etc. 